\title{
INVERSION ESTIMATES OF METHANE EMISSION IN THE MIDDLE EAST IN 2010-2017 WITH GOSAT OBSERVATIONS
}

\section{Wang, Fenjuan}

IEEE

2020

Wang , F, Maksyutov , S , Janardanan , R, Tsuruta , A, Ito , A , Morino , I, Yoshida , Y, Kaiser , J W , Janssens-Maenhout, G , Dlugokencky , E, Mammarella , I , Lavric , J V \& Matsunaga , T 2020 , INVERSION ESTIMATES OF METHANE EMISSION IN THE MIDDLE EAST IN 2010-2017 WITH GOSAT OBSERVATIONS . in IGARSS 2020 - 2020 IEEE INTERNATIONAL GEOSCIENCE AND REMOTE SENSING SYMPOSIUM . , 9323691 , IEEE International Symposium on Geoscience and Remote Sensing IGARSS, IEEE, pp. 1082-1085, IEEE International Geoscience and Remote Sensing Symposium (IGARSS), 26/09/2020 . https://doi.org/10.1109/IGARSS39084.2020.9323691

http://hdl.handle.net/10138/336780

https://doi.org/10.1109/IGARSS39084.2020.9323691

acceptedVersion

Downloaded from Helda, University of Helsinki institutional repository.

This is an electronic reprint of the original article.

This reprint may differ from the original in pagination and typographic detail.

Please cite the original version. 


\title{
INVERSION ESTIMATES OF METHANE EMISSION IN THE MIDDLE EAST IN 2010-2017 WITH GOSAT OBSERVATIONS
}

\author{
Fenjuan Wang, ${ }^{1,2,}$, Shamil Maksyutov ${ }^{1}$, Rajesh Janardanan ${ }^{1}$, Aki Tsuruta ${ }^{3}$, Akihiko Ito', Isamu Morino ${ }^{1}$, Yukio \\ Yoshida ${ }^{1}$, Johannes W. Kaiser ${ }^{4}$, Greet Janssens-Maenhout ${ }^{5}$, Ed Dlugokencky ${ }^{6}$, Ivan Mammarella ${ }^{7}$, Jost V. \\ Lavric $^{8}$, and Tsuneo Matsunaga ${ }^{1}$
}

1. Center for Global Environmental Research, National Institute for Environmental Studies, Tsukuba, 305-8506, Japan

2. Department of Climate Change, National Climate Center, Beijing,100081, China

3. Finnish Meteorological Institute, Helsinki, 00560, Finland

4. Deutscher Wetterdienst, Offenbach, 63067, Germany

5. European Commission Joint Research Centre, Ispra, 21027, Italy

6. Earth System Research Laboratory, NOAA, Boulder, CO 80305-3328, USA

7. Institute for Atmospheric and Earth System Research (INAR)/Physics, Faculty of Science, University of Helsinki, 00560, Finland

8. Max Planck Institute for Biogeochemistry, Jena, 07745, Germany

\begin{abstract}
Ten years of Greenhouse gas Observing SATellite (GOSAT) observation achieves valuable retrievals for top-down methane $\left(\mathrm{CH}_{4}\right)$ emissions estimates especially in regions lacking ground-based observations. This paper presents the long-term 2010-2017 trend in $\mathrm{CH}_{4}$ emissions in the Middle East countries. We use a global $0.1^{\circ} \times 0.1^{\circ}$ high-resolution inverse model, NIES-TM-FLEXPART-VAR (NTFVAR) with GOSAT retrievals and surface observations. Prior fluxes contain adjusted EDGAR v4.3.2 scaled to match the country totals by national reports to the United Nations Framework Convention on Climate Change (UNFCCC), augmented by biomass burning emissions from Global Fire Assimilation System (GFASv1.2) and wetlands emissions from Vegetation Integrative Simulator for Trace Gases (VISIT) model. The result shows the total annual $\mathrm{CH}_{4}$ emission of $23.54 \mathrm{Tg} \mathrm{CH}_{4} \mathrm{yr}^{-1}$ in the Middle East with more than $95 \%$ emissions from anthropogenic sources, and there is no statistically significant emissions trend from 2010 to 2017.
\end{abstract}

Index Terms - GOSAT, methane emissions, Middle East countries

\section{INTRODUCTION}

GOSAT, in operation since 2009, is the world's first satellite dedicated to greenhouse-gas-monitoring. It retrieves the column-averaged dry air mole fraction of atmospheric carbon dioxide $\left(\mathrm{XCO}_{2}\right)$ and methane $\left(\mathrm{XCH}_{4}\right)$ globally covering many places where surface observations are sparse. GOSAT retrievals have been widely used for top-down greenhouse estimations by inverse models, proven worthy for emission inventory evaluation (e.g., [1-8]).

There is the growing concern that $\mathrm{CH}_{4}$ emissions undermine the net climate benefit of using it as fuel, as it is short-lived greenhouse gas and a pollutant having adverse impacts on human health (eg., [9]) and ecosystem productivity [10]. GOSAT retrievals show that $\mathrm{XCH}_{4}$ are high in Asia, West Africa and the Middle East [11]. A few studies have addressed the $\mathrm{CH}_{4}$ emission in the Middle East, which accounts for one-third of global oil production, onesixth of gas production, $48 \%$ of proven oil reserves and $38 \%$ of proven gas reserves. Oil and gas production systems emit $\mathrm{CH}_{4}$ both from normal operations and system disruptions. In this paper, we present the long-term 2010-2017 trend in $\mathrm{CH}_{4}$ emissions in the Middle East derived with a $0.1^{\circ} \times 0.1^{\circ}$ highresolution inverse model at country scale.

\section{METHODOLOGY}

The global Eulerian-Lagrangian coupled model NIES-TMFLEXPART-VAR (NTFVAR) consists of the National Institute for Environmental Studies (NIES) model as a Eulerian three-dimensional transport model (TM), and FLEXPART (FLEXible PARTicle dispersion model) as the Lagrangian Particle Dispersion Model (LPDM) [12, 13]. Flux corrections were estimated independently for two categories of emissions (anthropogenic and natural). Variational optimization was applied to obtain flux corrections as two sets of scaling factors to vary prior uncertainty fields on a monthly basis at a $0.1^{\circ} \times 0.1^{\circ}$ resolution separately for anthropogenic and natural wetland emissions. More description of model settings is in our previous paper [14]. Prior $\mathrm{CH}_{4}$ fluxes used in the model included anthropogenic emissions, natural emissions from 
wetlands, soil sink, emissions from biomass burning and other natural sources from the ocean, geological reservoirs and termites. Annual anthropogenic emissions were taken from the Emissions Database for Global Atmospheric Research (EDGAR v4.3.2) at a spatial resolution of $0.1^{\circ} \times 0.1^{\circ}$ scaled to match the country reports to the UNFCCC, including monthly variability. Beyond 2012 we used the report from PBL Netherlands Environmental Assessment Agency [15] to extend EDGAR values of 2012 using equation (1), where $t$ is year from 2013 to 2017:

$E_{U N F C C C}(t)=E_{U N F C C C}(2012) \times \frac{P B L_{C H}(t)}{P B L_{C H}(2012)}$

In addition to the GOSAT retrievals (NIES, Level 2 retrievals, v. 02.72), we used ground based atmospheric $\mathrm{CH}_{4}$ observations in the inversions (for more details refer to [13]). The meteorological data used for the transport model were obtained from the Japanese Meteorological Agency (JMA) Climate Data Assimilation System (JCDAS) [16].

\section{RESULTS AND DISCUSSION}

The anthropogenic and natural $\mathrm{CH}_{4}$ emissions in 2010-2017 were estimated by the NTFVAR inverse model. The optimized average anthropogenic $\mathrm{CH}_{4}$ emission for the Middle East for 2010-2017 is $22.44 \pm 0.57 \mathrm{Tg} \mathrm{CH}_{4} \mathrm{yr}^{-1}$ (mean \pm standard deviation), sharing more than $95 \%$ of total $\mathrm{CH}_{4}$ emissions from the region (23.54 $\pm 0.62 \mathrm{Tg} \mathrm{CH}_{4} \mathrm{yr}^{-1}$ with an uncertainty of $3.30 \mathrm{Tg} \mathrm{CH}_{4} \mathrm{yr}^{-1}$ ) in the Middle East. The estimated anthropogenic emission in the Middle East is similar in magnitude to that in Europe (23.9 $\mathrm{Tg} \mathrm{CH}_{4} \mathrm{yr}^{-1}$ ) [13].

Average total $\mathrm{CH}_{4}$ emissions for each country in the Middle East are shown in Figure 1. The five countries emitting more than $1 \mathrm{Tg} \mathrm{CH}_{4} \mathrm{yr}^{-1}$ are Iran, Turkey, Saudi Arabia, Iraq and Egypt, with average total $\mathrm{CH}_{4}$ emissions of 6.45 $\mathrm{Tg} \mathrm{CH}_{4} \mathrm{yr}^{-1}, 3.64 \mathrm{Tg} \mathrm{CH}_{4} \mathrm{yr}^{-1}, 2.90 \mathrm{Tg} \mathrm{CH}_{4} \mathrm{yr}^{-1}, 2.87$ $\mathrm{Tg} \mathrm{CH}_{4} \mathrm{yr}^{-1}$ and $2.06 \mathrm{Tg} \mathrm{CH}_{4} \mathrm{yr}^{-1}$, respectively.

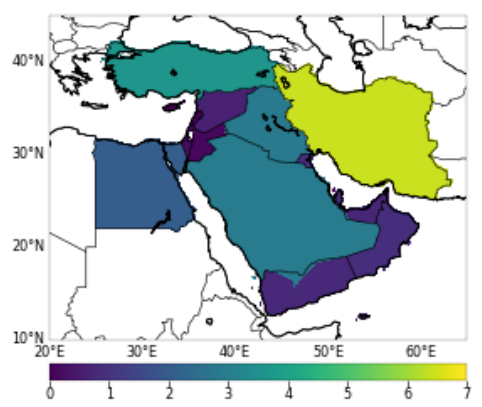

Figure 1. The average (2010-2017) optimized annual total $\mathrm{CH}_{4}$ emissions for each country in the Middle East (unit Tg $\left.\mathrm{CH}_{4} \mathrm{yr}^{-1}\right)$.

The interannual variation of total $\mathrm{CH}_{4}$ emissions in the five top-emitting countries and the Middle East is shown in Figure 2. There is no significant statistic trend in the total emission from 2010 to 2017, with a maximum in 2014 (24.76 $\left.\mathrm{Tg} \mathrm{CH}_{4} \mathrm{yr}^{-1}\right)$ and minimum in $2015\left(22.85 \mathrm{Tg} \mathrm{CH}_{4} \mathrm{yr}^{-1}\right)$. We detected statistically significant decreasing trends in Iran, Yemen and Syria, for the eight years period by using the Mann-Kendall trend test.

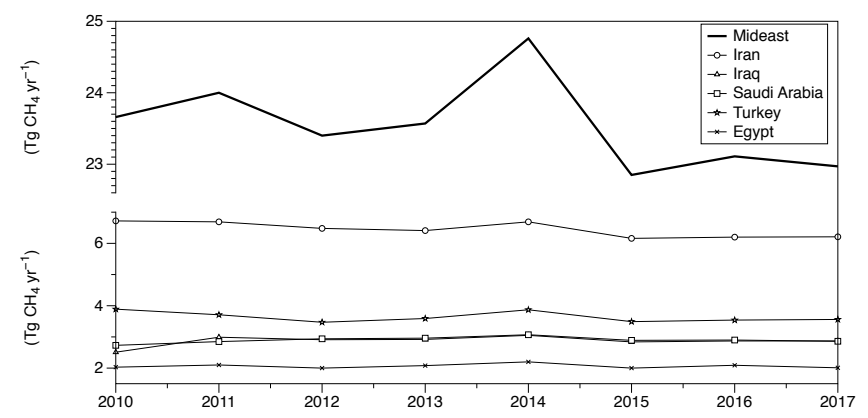

Figure 2. The interannual variation of optimized total $\mathrm{CH}_{4}$ emissions in the whole Middle East area and the five topemitting countries.

Anthropogenic fluxes in the Middle East and surroundings are shown in Figure 3. Hot spots are located around the Persian Gulf and its coast areas, where locate the world's largest single source of petroleum, concentrated oil and gas fields. Anthropogenic emissions are the dominant methane emission in the Middle East, as the Middle East is highlighted as the region of oil and natural gas producers in the world. The flaring, venting and combustion processes produce large amounts of $\mathrm{CH}_{4}$, which induce severe air pollution and climate warming. In recent years, the air quality in this region has worsened dramatically and concurrently global warming is especially strong [17]. Reduction of $\mathrm{CH}_{4}$ emissions from oil or gas production to final consumer will bring benefits in a short term to reduce the vulnerability of climate warming regarding extreme heat, scarce water resources, potentially increasing migration and risk of conflict in the region.

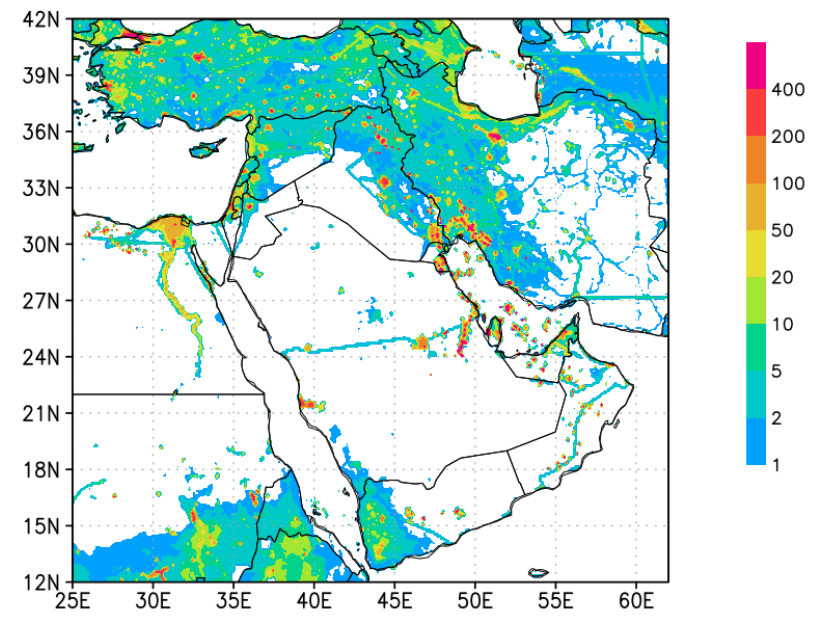

Figure 3. The average (2010-2017) posterior fluxes for anthropogenic $\mathrm{CH}_{4}$ emissions in the Middle East (mg CH 4 $\mathrm{m}^{-2}$ day $\left.^{-1}\right)$. 


\section{SUMMARY}

Long-term retrievals of column-averaged $\mathrm{CH}_{4}$ from GOSAT observations are used to estimate the top-down $\mathrm{CH}_{4}$ emissions in the Middle East with the $0.1^{\circ} \times 0.1^{\circ}$ highresolution inverse model NTFVAR. Although there is no statistically significant trend in regional total $\mathrm{CH}_{4}$ emissions from 2010 to 2017, a significant decreasing trend is detected in the biggest emitting country Iran. It is found that anthropogenic sources are dominant over total $\mathrm{CH}_{4}$ emission in the study area.

\section{REFERENCES}

[1] P. Bergamaschi et al., "Inverse modeling of European CH4 emissions 2001-2006," Journal of Geophysical ResearchAtmospheres, Article vol. 115, NOV 30 2010, Art no. ARTN D22309, doi: 10.1029/2010JD014180.

[2] M. Brown, "Deduction of emissions of source gases using an objective inversion algorithm and a chemical-transport model," Journal of Geophysical ResearchAtmospheres, Article vol. 98, no. D7, pp. 12639-12660, JUL 20 1993, doi: 10.1029/93JD01003.

[3] J. Sheng et al., "High-resolution inversion of methane emissions in the Southeast US using SEAC(4)RS aircraft observations of atmospheric methane: anthropogenic and wetland sources," Atmospheric Chemistry and Physics, Article vol. 18, no. 9, pp. 6483-6491, MAY 7 2018, doi: 10.5194/acp-18-6483-2018.

[4] A. Turner et al., "Estimating global and North American methane emissions with high spatial resolution using GOSAT satellite data," Atmospheric Chemistry and Physics, Article vol. 15, no. 12, pp. 70497069, 2015, doi: 10.5194/acp-15-70492015.

[5] S. Miller et al., "Anthropogenic emissions of methane in the United States," (in English), Proceedings of the National Academy of Sciences of the United States of America, Article vol. 110, no. 50, pp.
20018-20022, DEC 10 2013, doi: 10.1073/pnas. 1314392110.

[6] S. Miller, A. Michalak, R. Detmers, O. Hasekamp, L. Bruhwiler, and S. Schwietzke, "China's coal mine methane regulations have not curbed growing emissions," Nature Communications, Article vol. 10, JAN 29 2019, Art no. ARTN 303, doi: 10.1038/s41467-01807891-7.

[7] J. Sheng et al., "2010-2016 methane trends over Canada, the United States, and Mexico observed by the GOSAT satellite: contributions from different source sectors," Atmospheric Chemistry and Physics, Article vol. 18, no. 16, pp. 1225712267, AUG 24 2018, doi: 10.5194/acp18-12257-2018.

[8] S. Maksyutov et al., "Regional CO2 flux estimates for 2009-2010 based on GOSAT and ground-based $\mathrm{CO} 2$ observations," Atmospheric Chemistry and Physics, Article vol. 13, no. 18, pp. 9351-9373, 2013, doi: 10.5194/acp-13-9351-2013.

[9] K. Smith et al., "Health and Climate Change 5 Public health benefits of strategies to reduce greenhouse-gas emissions: health implications of shortlived greenhouse pollutants," Lancet, Article vol. 374, no. 9707, pp. 2091-2103, DEC-JAN 2009, doi: 10.1016/S01406736(09)61716-5.

[10] W. Ren et al., "Effects of tropospheric ozone pollution on net primary productivity and carbon storage in terrestrial ecosystems of China,", Journal of Geophysical Research-Atmospheres, Article vol. 112, no. D22, NOV 17 2007, Art no. ARTN D22S09, doi: 10.1029/2007JD008521.

[11] E. Kivimaki et al., "Evaluation and Analysis of the Seasonal Cycle and Variability of the Trend from GOSAT Methane Retrievals," Remote Sensing, Article vol. 11, no. 7, APR 1 2019, Art no. ARTN 882, doi: 10.3390/rs11070882. 
[12] A. Ganshin et al., "A global coupled Eulerian-Lagrangian model and 1 x $1 \mathrm{~km}$ $\mathrm{CO} 2$ surface flux dataset for highresolution atmospheric $\mathrm{CO} 2$ transport simulations," Geoscientific Model Development, Article vol. 5, no. 1, pp. 231243, 2012, doi: 10.5194/gmd-5-231-2012.

[13] D. Belikov et al., "Adjoint of the global Eulerian-Lagrangian coupled atmospheric transport model (A-GELCA v1.0): development and validation," Geoscientific Model Development, Article vol. 9, no. 2, pp. 749-764, 2016, doi: 10.5194/gmd-9749-2016.

[14] F. Wang et al., "Methane Emission Estimates by the Global High-Resolution Inverse Model Using National Inventories,", Remote Sensing, Article vol. 11, no. 21, NOV 2019, Art no. ARTN 2489, doi: $10.3390 / \mathrm{rs} 11212489$.

[15] J. G. J. Olivier and J. A. H. W. Peters, "Trends in global $\mathrm{CO} 2$ and total greenhouse gas emissions: 2018 Report," ed: PBL Publishers, 2018.

[16] S. Kobayashi et al., "The JRA-55 Reanalysis: General Specifications and Basic Characteristics," Journal of the Meteorological Society of Japan, Article vol. 93, no. 1, pp. 5-48, 2015, doi: 10.2151/jmsj.2015-001.

[17]. A. Ukhov et al., " Study of SO2 Pollution in the Middle East Using MERRA-2, CAMS Data Assimilation Products, and High-Resolution WRF-Chem Simulations,"JGR Atmospheres, Article vol.125,no.6,pp.122,2020,doi.org/10.1029/ 2019JD031993

"C 2021 IEEE. Personal use of this material is permitted. Permission from IEEE must be obtained for all other uses, in any current or future media, including reprinting/republishing this material for advertising or promotional purposes, creating new collective works, for resale or redistribution to servers or lists, or reuse of any copyrighted component of this work in other works." 